\title{
The Satisfaction of Basic Educational Needs
}

\section{Christopher Colclough}

It is nothing new to argue that states should aim at providing universal access to basic services. What is new is the prominence which the basic needs debate gives to the achievement of this goal. The distributional implications of alternative development strategies are obviously important. The old emphasis upon economic growth too often did not make them explicit : at best it became a medium-term maximising strategy which relegated distributional issues to the future, and concentrated on generating a surplus which would then allow these issues to be addressed; it assumed that policy adjustments would be needed later but was silent about how and when these should occur. At worst it assumed that the process of growth would allow everyone to become richer willy nilly, that the distribution of income would not worsen, and that it might even improve with growth.

Both sets of assumptions have now been seriously challenged. In some societies economic growth has been clearly associated with a worsening of income distribution and an increase in the incidence of absolute poverty. And in others it seems to have helped create interest groups which make the process of redistribution more difficult than before. Thus the second set of assumptions seem to be false, and the first may have been politically naive. If it is true that distributional goals have always been implicit in growth maximising strategies (on the part of academic analysts if not always on the part of those who implement the policies), it seems desirable to redirect analytic attention in a way which incorporates these goals explicitly within the analysis.

The ways in which distributional goals are now generally talked about, however, so often seem to run the risk of further naivete. Though there may be general agreement that the development strategies and expenditure policies of governments need to shift in favour of benefiting the poorer groups, so often the shopping list of needs is specified in a way which assumes an incrementalist approach. It may be generally true that some shifts in the balance of public expenditure away from urban towards rural areas, away from hospitals towards health posts, away from corrugated iron towards thatch, will bring lasting benefits to the poorer people. But there is also a danger of underestimating the degree of structural change required in many societies if changes in expenditure patterns are to have a real impact upon the poorest groups. It is often not merely a question of altering the pattern of expenditure, but of promoting changes in the social and economic structures within which these expenditures take place. This argument will be illustrated by considering the case of education, which rightly features in most people's list of basic needs.

\begin{tabular}{|c|c|c|c|c|c|}
\hline \multicolumn{6}{|c|}{ Public Expenditure on Education in $1970^{\mathrm{a}}$} \\
\hline $\begin{array}{c}\text { Country } \\
\text { Groupings by level } \\
\text { of incomes per } \\
\text { capita }\end{array}$ & $\begin{array}{l}\text { As per cent of } \\
\text { budget }\end{array}$ & $\begin{array}{l}\text { As per cent of } \\
\text { GNP }\end{array}$ & $\begin{array}{c}\text { First level } \\
\text { enrolment ratio }\end{array}$ & $\begin{array}{l}\text { Second level } \\
\text { enrolment ratio }\end{array}$ & $\begin{array}{l}\text { Number of } \\
\text { countries }\end{array}$ \\
\hline less than $\$ 120 \ldots$ & 13,2 & 2,9 & 66 & 15 & 29 \\
\hline$\$ 120-\$ 250 \ldots$ & 18,9 & 3,8 & 83 & 19 & 23 \\
\hline$\$ 251-\$ 750 \ldots$ & 13,5 & 3,0 & 97 & 25 & 38 \\
\hline$\$ 751-\$ 1500 \ldots$ & 10,1 & 3,1 & 97 & 49 & 9 \\
\hline more than $\$ 1500$ & 17,8 & 5,8 & 100 & 83 & 24 \\
\hline
\end{tabular}

One way of assessing the extent to which the educational needs of the populations of poor countries are not being met is to look at enrolment ratios. This begs the question of whether the school system as it presently operates addresses the real needs of those who have access to it, an important question to which we return later. For the moment, however, the quantitative picture tells us something about the distribution of educational expenditures, even if it says little about their effectiveness.

The picture is a depressing one. The table shows that in 1970 the 29 poorest countries with a per capita income of less than $\$ 120$ had less than 70 per cent of 
their children aged 5-14 years (first level) and only about 15 per cent of those aged 15-19 years (second level) enrolled in schools. Although these figures are very much lower than in the richer countries, the proportion of the annual budget, and of GNP, spent on education is not so different, for the low ratios in the poorest countries arise from an overall shortage of resources, rather than a difference in the importance attached to educational expenditures by the State. If existing cost struct ures remain unchanged the expansion of school systems in the poorest countries will be heavily constrained, so that it is estimated that the number of children in the 5-14 years age-group who are not at school will increase from about 269 million in 1970 to about 375 million in 1985. Thus, on present trends, the number of people who do not have access to the full primary cycle and who cannot proceed into secondary school is likely to increase rapidly and the problem of supplying this particular basic need is expected to get substantially worse over the next decade.

A range of different solutions to this problem has been proposed. The most obvious area to explore is the possibility of reducing unit costs. At primary level this is difficult-class sizes are already very large, teaching materials are woefully inadequate, and teachers are often untrained and paid far less than those at higher levels of the system. Thus cost reduction proposals tend to concentrate on secondary and tertiary levels. Herc there are opportunities for reducing costs through cutting teachers' salaries or increasing the size or number of classes taught--particularly at the tertiary level. Nevertheless widespread demand for increased provision of secondary and tertiary places, even in the face of growing unemployment of school-leavers tends to undermine attempts to divert resources from the top to the base of the system, and many people believe that the potential benefits of unit cost reductions will be lost by the continued growth of enrolments at these levels.

There are those, however who have taken a different line. If the costs of the existing formal system seem so inflexible, and if the political difficultics of arresting the expansion of secondary and tertiary education are too great, perhaps one should think of designing a shorter, cheaper and more relevant education for those children whom the formal system excludes. It is recognised that existing primary schools are heavily influenced by the need to prepare children for secondary entrance. Yet most children will never go to secondaly schools, and will remain in the rural areas. A new basic education programme should therefore be introduced which emphasizes literacy, numeracy, knowledge required for running a household and bringing up a family, and the acquisition of some functional skills.
This concept of 'basic education' has gained a good deal of currency in the literature, and its adoption as a policy goal in the poorest countries has been promoted by a number of international aid and other agencies. ${ }^{1}$ Although similar schemes have become a popular part of adult and non-formal education programmes in many countries, they have rarely been seen as a means of giving a minimum basic education to children excluded from school. Now, however, rather than concentrating on reforming the existing educational structure it is argued that shorter, cheaper, alternative education programmes should be established, to serve as a substitute for primary schooling for at least part of the population.

But can a new approach to rural education geared explicitly to the requirements of rural life, and which does not allow for the possibility of children moving into the higher levels of the school system survive? There are strong a priori reasons for being sceptical. Even if new institutions with a new educational content are established, the problem is how to create in people the will to become better farmers rather than to attempt to join the formal sector with the potential of earning much greater rewards. Since the formal school system is seen by most poor people as the only means of achieving class mobility, it is probable that alternative education programmes which do not hold out this possibility would not be supported. Nevertheless, some countries have tried this kind of approach, and lessons can be drawn from their experiences.

In Upper Volta, a project was established in 1959 which essentially envisaged a dual system of education. ${ }^{2}$ Primary schools were to be given the principal role of providing education for those few who would go on to secondary school, ultimately to form the nation's elite. Everyone else would be given three years of agricultural vocational training combined with basic literacy and numeracy. The expansion of primary education was to be halted, and after 1970 most resources were to go to the rural education system on the grounds that the formal sector could be serviced by a comparatively small formal school system. Though there had been a significant expansion in rural education centres (RECs), reaching a total enrolment of 24,000 in 1973 , this was only about one-sixth of what had been planned. On the other hand, the primary school system continued to expand steadily, and to get the lion's share of the educational budget.

A recent evaluation of this scheme (IEDES and Grabe 1975) has shown that difficulties were caused by the existence of a dual system. Farents and students regarded the REC at best as a temporary

1 Sec. for exatmple, JBRD. 1974 and Ahmed and Coombs (eds.) 1975.

2 A more extended discussion can be found in Colelough, 1976. 
expedient to be replaced later by primary schooling and at worst as a form of discrimination against rural people. Though some agricultural skills were acquired, these often were not used on their return to the village owing to a lack of other inputs. Since rural life was not improved as much as had been hoped, and since the programme failed to open the door to the modern sector, it is hardly surprising that it has now begun to collapse. The dual system was seen to be discriminatory, and failed to win the acceptance, confidence and support of rural people.

A similar approach has been tried in Afghanistan where a system of 'village schools' has been developed to provide basic education for up to three years. The schools are established using local and self-help efforts, but once children begin to graduate from Grade 3 they are generally transformed into traditional primary schools. Phillips (1975) comments on other schemes in Madagascar and Benin:

"Madagascar introduced experimentally in 1962 a rural four-year basic cycle under which rural communities would participate and lower salaries would be paid by them than under the standard system. By 1970 the experiment was intended to cover 660 classes or 10 per cent of the elementary school pupils. In fact only about 100 were covered. The villages clamoured for 'real schools' and considered the plan undemocratic, as it would tie their children to the peasantry. Dahomey... experienced similar difficulties".

The final example is that of India, a country with possibly more experience than any other in attempting to run a dual primary education system first, when the British Administration attempted to introduce 'ruralised' curricula into rural schools, and more recently, when the Gandhian Basic Education movement resulted in more than 12 million enrolments in Basic schools by 1962-63.

Even before the turn of the century, the provinces of Bombay, Bengal and Central Provinces had introduced separate curricula for rural schools. But neither the teachers nor the parents had really been won over.

"The idea of separate ruralised curricula had by 1920 died out, having become unpopular among rural people who wished their sons to qualify for government service or admission to English schools, and who thought that the rural course was a sign of backwardness in education." (Sinclair 1976:3).

The Gandhian schemes for basic education were more successful. Gandhi deeply believed in the need for a radical system of education centred around productive work in order to prepare children for their future lives in rural areas, and, since budgetary constraints were acute, to cover the costs of elementary schooling. A scheme of Gandhian Basic National Education was accepted by Congress. Craft activities were to represent the largest part of each day's school time-table, supplemented by study of the social and natural environment, mathematics, drawing, music, language and physical training. In spite of tremendous problems of teacher supply and provision of equipment, after its adoption as national policy the movement spread quickly. But though the reaction of rural parents was initially good, since they were pleased to have the opportunity of an elementary education for their children, this eventually gave way to resentment of the more privileged educational opportunities available to urban children. Over the last 10 years there has been little expansion in the number of Basic Schools, and the principles they stood for have ceased to be an important element of national policy.

All this evidence seems to suggest that the design of policies to provide for basic educational needs is more complex than many people suppose. The real difficulties are caused by the existence of a relatively exclusive formal education system which performs an important socio-economic function for those who are enrolled in it. The school gives a possibility, however slight, of social mobility and individual parents and children believe it is against their interests to change this. These attitudes towards the role of the school systems will continue to be reinforced even in circumstances of growing unemployment among educated people. In the rural areas, demand for more provision of conventional primary schooling is likely to increase as development proceeds, and the obstacles to change are likely to become more entrenched.

Should poor countries therefore simply adopt a policy of gradual expansion and qualitative improvement of the primary schools, within budgetary limits? Such a policy is at least defensible in terms of popular acceptance and of the promotion of more equal opportunities for educational and social advancement. But in terms of its effects upon the welfare of the poorest nothing will have changed: most will still not proceed to secondary school, most will not get jobs in the formal sector, and most will find their school experience of little help or relevance to their future lives.

It seems, then, that neither dualistic nor incrementalist approaches to educational reform are likely to bring significant educational benefits to children in the poorest families. The main reason for this is that it is not possible to find a purely educational answer to a problem that has social, economic and political 
as well as education dimensions. Reforms which properly speak to the educational needs of the poorest groups will need to embrace fairly profound changes in the structure and content of the whole school system, and in its institutional links to the labour market. Several countries are introducing changes along these lines. Though there are differences in the importance attached to changes in curricula, in examinations and systems of selection, and in the incomes earned from formal employment, some countries believe that all of these institutions need to be changed if schools are to be of benefit to the poorest groups. ${ }^{3}$ Though experience is still limited, the evidence suggests that this is a much more promising stfategy than that of adopting an incremental approach which leaves the existing school/work structure relatively unchanged.

3 See particularly Government of Zumbia, 1976.

\section{References}

Ahmed, M. and P. H. Coombs, (eds.), 1975, Education for Rural Development: Case Studies for Planners, ICED, Praeger

Colclough, Christopher, 1976 'Basic Education: Samson or Delilah?', in Convergence IX, 2 (Toronto)

Government of Zambia, 1976, Education for Development, Ministry of Education, Lusaka (mimeo)

IBRD, 1974, Education Sector Working Paper, Washington

IEDES and Grabe, Sven, 1975, 'Upper Volta: A Rural Alternative to Primary Schools', in Ahmed and Coombs (eds.), 1975

Phillips, H. M., 1975, Basic Eclucation, a World Challenge, Wiley, London

Sinclair, Margaret, 1976 'Gandhian Basic Education', Institute of Development Studies, Sussex (mimeo) 